\title{
Relação entre a lagarta-do-cartucho e seus agentes de controle biológico natural na produção de milho
}

\author{
Maria de Lourdes Corrêa Figueiredo(1), Angélica Maria Penteado Martins-Dias ${ }^{(2)}$ e Ivan Cruz $^{(1)}$
}

\begin{abstract}
(1)Embrapa Milho e Sorgo, Caixa Postal 151, CEP 35701-970 Sete Lagoas, MG. E-mail: lude@cnpms.embrapa.br, ivancruz@cnpms.embrapa.br (2)Universidade Federal de São Carlos, Dep. de Biologia Evolutiva, Caixa Postal 676, CEP 13565-905 São Carlos, SP. E-mail: angelica@power.ufscar.br
\end{abstract}

\begin{abstract}
Resumo - Este trabalho teve como objetivo quantificar as perdas na cultura do milho BRS 3123 decorrentes do ataque da lagarta-do-cartucho (Spodoptera frugiperda), na ausência e presença de seus inimigos naturais. Aos 15 dias depois da emergência da planta, foi realizada uma infestação artificial da praga (uma postura por metro quadrado). As lagartas alimentaram-se da planta, sem a interferência de seus inimigos naturais, pela utilização de uma gaiola de proteção (inicial, de dois dias depois da infestação, até uma proteção máxima de 16 dias). O dano da praga, determinado por uma escala de notas de 0 (plantas sem dano) a 5 (plantas mortas), foi em média de 4,01, 1,39, 1,09 e 0,93 para o período de proteção da praga de 16, 6, 4 e 2 dias, respectivamente. Na ausência de agentes de controle biológico, o ataque da praga ocasionou perdas na produção de matéria seca de $47,27 \%$ e perdas no rendimento de grãos de $54,49 \%$. Os resultados evidenciaram a importância dos inimigos naturais na supressão de lagartas de $S$. frugiperda na cultura de milho.
\end{abstract}

Termos para indexação: Spodoptera frugiperda, inimigos naturais, silagem, produtividade de milho.

\section{Relationship between fall armyworm and their natural biological control agents in the maize crop}

\begin{abstract}
This work had the objective of quantifying the losses in the maize hybrid BRS 3123 due to the attack of fall armyworm (Spodoptera frugiperda), in the absence or presence of its natural enemies. Fifteen days after the plant emergency, an artificial infestation (one egg mass per square meter) was accomplished. The larvae fed on the plant, without the interference of its natural enemies, by using an appropriated protection cage (initial protection for two days after infestation, until a maximum protection period of 16 days). The damage caused by the pest, determined through a visual scale from 0 (plants without damage) to 5 (dead plants), was on average, 4.01, 1.39, 1.09 and 0.93 for the pest protection period of 16, 6, 4 and 2 days, respectively. In the absence of the biological control agents, the attack of the pest caused losses of $47.27 \%$ in the dry matter production and losses of $54.49 \%$ in grain yield. The results evidenced the importance of natural enemies in the suppression of fall armyworm in maize crop.
\end{abstract}

Index terms: Spodoptera frugiperda, natural enemies, silage, maize yield.

\section{Introdução}

A lagarta-do-cartucho, Spodoptera frugiperda (J.E. Smith, 1797) (Lepidoptera: Noctuidae) é a principal praga da cultura do milho, e ocorre em todas as regiões produtoras, tanto nos cultivos de verão, quanto nos de segunda safra (safrinha). A espécie ataca a planta desde sua emergência até a formação de espigas (Cruz, 1995).

No Brasil, o milho tem ocupado cerca de 13 milhões de hectares com produção média de 45 milhões de toneladas por ano (Brasil, 2004), acarretando prejuízos causados pela lagarta-do-cartucho estimados em mais de 400 milhões de dólares anualmente (Cruz et al., 1999). Quando essa praga ataca plantas de até 30 dias, ela pode causar sua morte e reduzir o estande inicial e, em plantas maiores, pode comprometer a produtividade ao alimentar-se do parênquima das folhas, do broto central da planta (cartucho-do-milho) e dos grãos da espiga (Cruz \& Turpin, 1983; Cruz et al., 1999).

Apesar dos avanços da pesquisa, S. frugiperda ainda é a praga que mais ataca a cultura do milho, não só no Brasil, mas em toda a América (Wiseman et al., 1966; Cruz, 1995; Cruz et al., 1999). 
Os prejuízos não estão relacionados à ausência de tratamento fitossanitário, pois o número de aplicações tem aumentado ao longo dos anos e, em algumas regiões, é comum a utilização de mais de cinco aplicações de inseticidas durante a safra. No momento, a preocupação é com a ocorrência de populações resistentes aos produtos químicos, verificada em algumas regiões, e a diminuição da diversidade de agentes de controle biológico, em conseqüência do uso inadequado dos pesticidas (Cruz et al., 2002).

Há interesse em reduzir o uso de produtos fitossanitários, estimulando a implementação do manejo integrado de pragas. Essa tendência demonstra necessidade por melhores métodos de avaliação da atuação de inimigos naturais nos agroecossistemas (Lenteren, 2000). Um desses métodos é baseado na utilização de gaiolas de proteção de pragas contra seus inimigos naturais (técnica de exclusão com gaiolas), conforme Van den Bosch et al. (1969).

Esse método foi utilizado para avaliar a eficácia de inimigos naturais na supressão de diferentes presas ou espécies hospedeiras, avaliando, muitas vezes, o potencial de dano da praga, na ausência de seus inimigos naturais (Lingren et al., 1968; Van den Bosch et al., 1969; Irwin et al., 1974).

Este trabalho teve como objetivo quantificar as perdas na cultura do milho em decorrência do ataque de $S$. frugiperda, na ausência e presença de seus inimigos naturais, em diferentes períodos de desenvolvimento (período larval), utilizando o método de exclusão por gaiolas a partir de infestação artificial (posturas da praga fixadas em plantas de milho).

\section{Material e Métodos}

O experimento foi conduzido na Embrapa Milho e Sorgo, em Sete Lagoas, MG, em 2001/2002, utilizando o milho híbrido BRS 3123, em plantio direto. Segundo Melo et al. (1999), os híbridos em geral possuem alta porcentagem de espigas na massa verde, (acima de 40\%), digestibilidade acima de $70 \%$, e $\mathrm{pH}$ menor que 4,6, o que confere alto potencial para produção de matéria seca e de silagem com ótima qualidade.

O delineamento foi em blocos ao acaso, com nove tratamentos e cinco repetições. Cada parcela foi constituída por quatro fileiras de milho com $3 \mathrm{~m}$ de comprimento, e cinco plantas de cada linha foram protegidas com gaiolas de armação de ferro, fixadas no solo, cobertas com capas de voile (malha de $0,1 \mathrm{~mm}$ ) de 1,2x1,0x0,5 m, logo depois da emergência das plantas.
Quinze dias depois da emergência das plantas, foi realizada a infestação, com uma postura da praga por metro quadrado grampeada na folha de milho, em uma das cinco plantas que, logo em seguida, foram protegidas pela gaiola. Cada postura continha cerca de 100 ovos, com 24 horas de desenvolvimento embrionário. Parcelas infestadas artificialmente, porém, sem gaiolas foram definidas como tratamento testemunha.

Os tratamentos foram constituídos de diferentes épocas de retirada das gaiolas. Os insetos ficaram protegidos pela gaiola por períodos entre dois e 16 dias depois da infestação, com intervalos de dois dias. A cada dois dias, as gaiolas eram retiradas de acordo com os tratamentos, e a praga, daí em diante, ficou sujeita à ação de diferentes agentes de controle presentes na área. A primeira retirada da gaiola teve início com as larvas recém-eclodidas. Dessa maneira, excluiu-se a possibilidade de atuação de predadores e parasitóides de ovos.

O dano ocasionado pela praga foi avaliado por meio de uma escala visual de notas, aplicada individualmente às plantas, depois da remoção das gaiolas do último tratamento. Na aplicação da escala de notas (Cruz et al., 1999) foi considerado o dano nas seis folhas centrais: 0 , ausência de folhas danificadas; 1 , presença de raspadura nas folhas; 2, presença de furo nas folhas; 3 , presença de dano nas folhas e alguma lesão no cartucho; 4, presença de cartucho destruído; e 5, plantas mortas.

Quando as espigas estavam com 60\% de umidade, fase de colheita para a produção de silagem, foram colhidas individualmente, de uma fileira escolhida ao acaso, as cinco plantas que estavam sob a gaiola, para avaliação da massa produzida em cada parcela. Depois do cálculo do peso fresco de cada parcela, foram amostrados $300 \mathrm{~g}$ de matéria verde, secados em estufa de fluxo fechado a $105^{\circ} \mathrm{C}$, até a obtenção de peso constante, para a determinação da porcentagem de matéria seca. Com esse resultado, foi realizado o cálculo da produtividade de matéria seca.

Depois da maturação fisiológica (espigas com 13\% de umidade), colheram-se todas as plantas, que ficaram sob as gaiolas nas demais parcelas, e também as plantas das parcelas testemunhas para determinar o número de espigas e o rendimento de grãos (produtividade) de cada tratamento.

Os dados foram submetidos à análise de regressão e de variância, e as médias comparadas pelo teste de Duncan, a $5 \%$ de probabilidade. Os resultados 
referentes à nota de dano e número de espigas foram transformados em $(x+0,5)^{0,5}$, para realização de análise de variância e comparação das médias.

A presença de parasitóides na área foi confirmada por um segundo experimento, plantado no mesmo dia, com o mesmo número e tamanho de parcelas, e ao lado deste, no qual eram realizadas coletas de plantas de milho a cada dois dias, coincidindo com a retirada das gaiolas. As folhas de milho foram abertas e as larvas de S. frugiperda coletadas e individualizadas em recipientes contendo dieta artificial. As larvas foram avaliadas até a constatação do parasitismo ou viabilidade do adulto da praga. Durante a avaliação das plantas, também foi computada a ocorrência de predadores.

\section{Resultados e Discussão}

Os danos provocados pela praga variaram conforme o período em que ela permaneceu protegida de seus inimigos naturais dentro da gaiola. Nas parcelas em que as plantas foram mantidas sob as gaiolas pelo período máximo estipulado, 16 dias, o dano foi o maior (Figura 1), atingindo uma nota média de 4,01. Durante esse período, 33\% das plantas receberam a nota máxima (nota 5) e 52\% a nota 4 (Figura 2). Situação similar aconteceu quando a praga foi mantida sob proteção por 14 dias, sendo as plantas classificadas com uma média de dano de 3,45 .

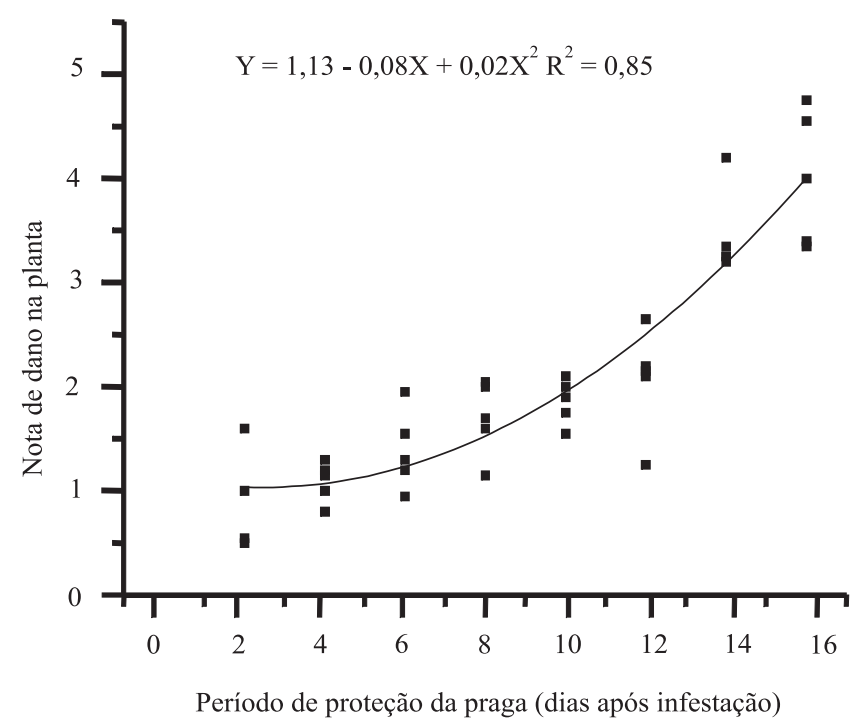

Figura 1. Relação de notas de dano de Spodoptera frugiperda na cultura do milho híbrido BRS 3123, em função dos diferentes períodos de proteção da praga, em relação a seus inimigos naturais.
Quando a praga ficou protegida por períodos entre oito e 12 dias, não houve diferença significativa entre o dano provocado às plantas, sendo a nota média de dano equivalente a 1,88. Neste intervalo, houve maior ocorrência de nota 2 (Figura 2).

Nos períodos em que a praga ficou protegida por quatro e seis dias, as notas médias de dano foram, respectivamente, 1,09 e 1,39, com predominância da nota 1 . As médias nesses períodos também não diferiram entre si. Quando as gaiolas foram retiradas das plantas nesses tratamentos, as larvas eram de primeiro e de segundo ínstar e estavam sujeitas aos mesmos inimigos naturais. No tratamento em que a proteção da praga durou apenas dois dias, observou-se menor dano às plantas, com nota média de 0,93. Esta média não diferiu significativamente da verificada nas plantas das parcelas testemunhas, cuja média foi de 0,86. Nesses dois tratamentos houve concentração de notas zero e um (Figura 2), o que indica maior vulnerabilidade da praga a seus inimigos naturais, nesse estágio.

Resultados semelhantes foram observados por Figueiredo et al. (1999), ao comparar o efeito de liberações de Telenomus remus (Hymenoptera: Scelionidae), sozinho ou associado ao Baculovirus spodoptera ou ao inseticida lambdacialotrina para controle de $S$. frugiperda, os autores verificaram que, nas parcelas testemunhas, onde a praga e os inimigos naturais atuaram livremente, a nota média de dano foi 1,11, e que nos demais tratamentos, as notas médias de dano ficaram abaixo de 1,0. Resultados comparativos sobre o dano causado por $S$. frugiperda na cultura do milho, na ausência de seus inimigos naturais, usando o método descrito, ainda não foram relatados.

No ajuste dos dados, por meio da análise de regressão, entre período de proteção da praga e dano na planta, obteve-se o melhor ajuste com a função quadrática. O coeficiente de determinação obtido foi significativo $\left(\mathrm{Y}=1,13-0,08 \mathrm{X}+0,02 \mathrm{X}^{2}, \mathrm{R}^{2}=0,85\right)$. $\mathrm{O}$ coeficiente $\mathrm{b}$ negativo demonstra alta relação entre o período de proteção e o dano na planta, indicando que, quanto maior o período de proteção, maior o dano causado pela praga (Figura 1).

Entre os principais inimigos naturais de $S$. frugiperda, no Brasil, destacam-se predadores e parasitóides de ovos e de lagartas (Cruz, 1995, 2002; Figueiredo, 2004).

Entre os inimigos naturais presentes na área foram observados o predador de ovos e larvas Doru luteipes Scudder (Dermaptera: Forficulidae), o parasitóide de ovo/larva Chelonus insularis (Cresson) (Hymenoptera: 
Braconidae) e os parasitóides de larvas Eiphosoma laphygmae Costa Lima (Hymenoptera: Ichneumonidae), Campoletis flavicincta (Ashmead) (Hymenoptera: Ichneumonidae), Exasticolus fuscicornis (Cameron) (Hymenoptera: Braconidae), Cotesia marginiventris (Cresson) (Hymenoptera: Braconidae), Eiphosoma vitticole Cresson (Hymenoptera: Ichneumonidae), Pristomerus spinator (Fabricius) (Hymenoptera: Ichneumonidae) e Archytas incertus (Macquart) (Diptera: Tachinidae). Em menor proporção, foram coletados nas folhas de milho outros predadores, como Orius sp. (Heteroptera: Anthocoridae), Coccinellidae, Formicidae, Coleoptera, Heteroptera, Araneae e Hymenoptera.

Vespas do gênero Polistes foram observadas principalmente no momento da retirada das gaiolas, provavelmente atraídas por substâncias exaladas das plantas danificadas ou das lagartas. Prezoto \& Machado (1999) destacaram a participação de espécies incluídas no gênero Polistes spp. como agentes importantes no
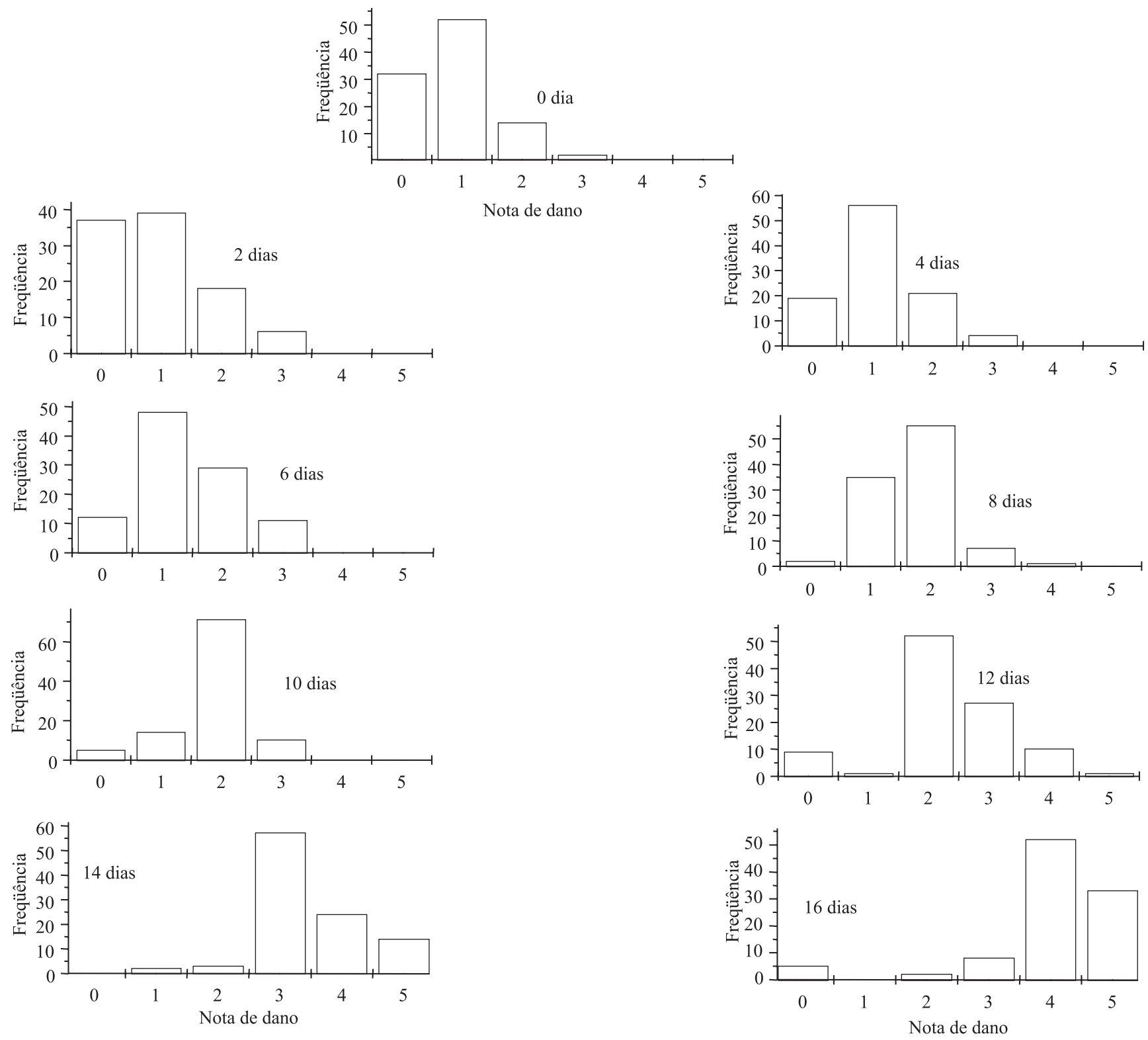

Figura 2. Freqüência de notas de dano de Spodoptera frugiperda na cultura do milho híbrido BRS 3123, em função de diferentes períodos de proteção da praga (2-16 dias após a infestação), em relação aos seus inimigos naturais. 
controle de pragas agrícolas, pela quantidade de indivíduos utilizados em sua dieta. Essas vespas são fundamentais no controle de $S$. frugiperda, porém seu comportamento ainda requer estudos. Prezoto \& Machado (1999) sugerem a utilização de colônias de $P$. simillimus dentro da cultura do milho como estratégia de manejo de S. frugiperda.

É possível, portanto, considerar a presença de inimigos naturais na área, como responsável pelos baixos índices de dano, nos tratamentos em que a praga ficou protegida por período inferior a dez dias.

O número de plantas nas parcelas por ocasião da colheita no ponto de silagem não variou significativamente entre os diferentes tratamentos. No entanto, quando se calculou a matéria seca das plantas, que é um dos parâmetros para medir a produtividade de silagem, os valores obtidos variaram de 6.780 a $12.860 \mathrm{~kg} \mathrm{ha}^{-1}$. O maior rendimento do híbrido foi próximo do encontrado por Gomes et al. (2002), ao avaliarem diferentes híbridos na região de Sete Lagoas, MG, cuja produtividade média de matéria seca foi de $12.500 \mathrm{~kg} \mathrm{ha}^{-1}$.

As maiores quantidades de matéria seca, cujos valores variaram de 12.860 a $10.540 \mathrm{~kg} \mathrm{ha}^{-1}$, foram obtidas nas parcelas em que a praga permaneceu protegida por menor período, portanto, sujeitas a ação dos inimigos naturais por um tempo maior (Figura 3). Ao contrário, quando a praga foi mantida protegida pelas gaiolas por períodos entre 14 e 16 dias, houve maior redução na produção de matéria seca. A relação entre

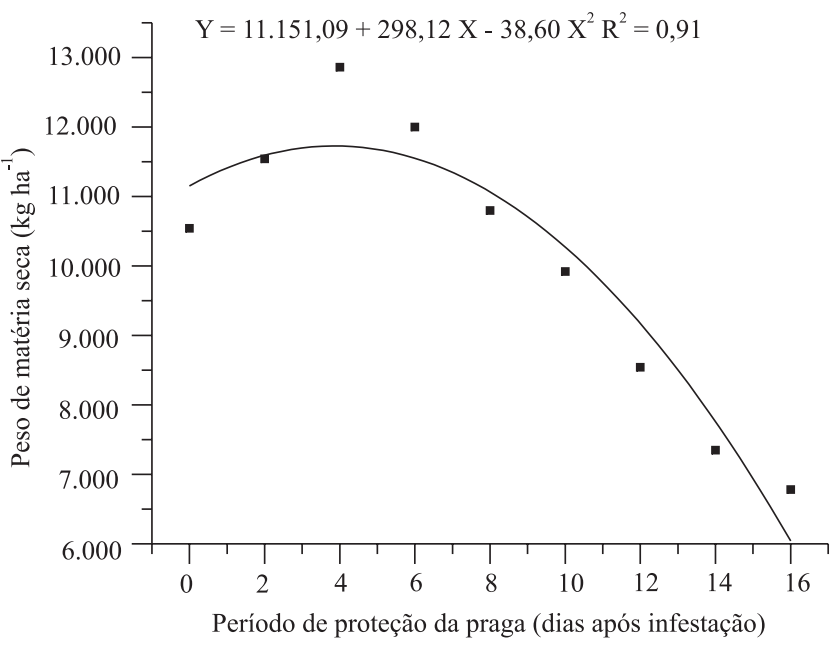

Figura 3. Curva da produtividade da matéria seca em milho híbrido BRS 3123 (silagem), em função dos diferentes períodos de proteção de Spodoptera frugiperda, em relação aos seus inimigos naturais. produção de matéria seca e período de proteção da praga foi significativamente descrita pela equação $\mathrm{Y}=11.151,09+298,12 \mathrm{X}-38,60 \mathrm{X}^{2}\left(\mathrm{R}^{2}=0,91\right)$, demonstrando que a intesidade do dano de S. frugiperda se relacionou à ausência dos inimigos naturais, o que provocou a redução na produção de matéria seca.

$\mathrm{Na}$ consideração dos valores extremos de rendimento de matéria seca, observa-se uma perda de $47,27 \%$ de acordo com o ataque da lagarta-do-cartucho. Uma vez que a porção nutritiva de um alimento está contida na matéria seca e que a capacidade de consumo dos alimentos pelos animais (bovinos) está relacionada, também, com a matéria seca, todo cálculo relativo à alimentação, tais como balanceamento de rações, custo de aquisição e transporte de alimentos, deve ser feito com base nesse parâmetro, portanto a perda de matéria seca afeta diretamente a nutrição animal e, conseqüentemente seu custo.

Quanto ao rendimento de grãos, foi também observada diferença significativa entre as médias obtidas nas parcelas em que a praga foi protegida por menor ou maior período, respectivamente, 6.350 e $2.890 \mathrm{~kg} \mathrm{ha}^{-1}$. Portanto, o rendimento na produtividade para o híbrido triplo BRS 3123 foi comprometido em 54,49\%. Esse resultado foi maior do que os obtidos por Cruz et al. (1999, 2002), Cruz \& Turpin (1983) e Marenco et al. (1992), que relataram perdas ao redor de $20 \%$ devido ao ataque da praga. Nesses trabalhos, a praga estava sujeita à livre-ação de seus inimigos naturais.

Quando a praga ficou protegida somente por dois dias, a produtividade foi de $6.350 \mathrm{~kg} \mathrm{ha}^{-1}$. Valor semelhante ao encontrado neste trabalho foi observado por Monteiro (1998), cuja produtividade média foi de $6.317 \mathrm{~kg} \mathrm{ha}^{-1}$ para o mesmo híbrido em Sete Lagoas, MG. O prejuízo causado pelas lagartas de $S$. frugiperda, quando protegidas de seus inimigos naturais, até 16 dias após a infestação, evidencia o quanto essa praga afeta diretamente a produtividade na cultura do milho. Os maiores rendimentos foram obtidos nas parcelas em que a praga ficou protegida por menores períodos. Esses resultados são observados pelo gráfico de regressão, em que a curva apresenta um decréscimo para o peso de grãos a partir de dez dias após a infestação (Figura 4). Essa redução do peso de grãos pode estar relacionada diretamente com a redução do número de grãos por espigas, conforme salientado por Cruz \& Turpin (1983). 


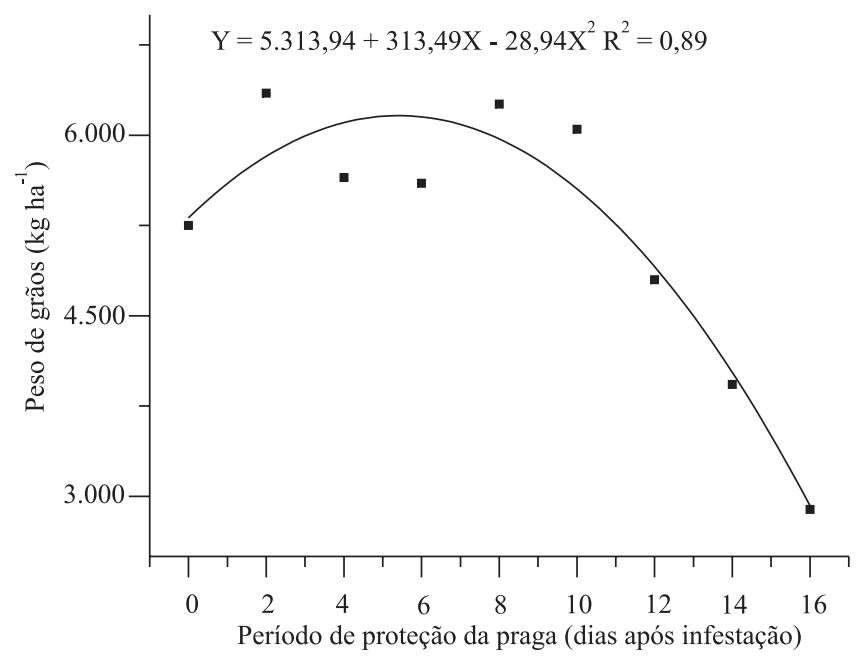

Figura 4. Curva de produtividade de grãos de milho híbrido BRS 3123, devido aos danos ocasionados por Spodoptera frugiperda, quando protegida de seus inimigos naturais.

\section{Conclusão}

A intensidade dos danos de Spodoptera frugiperda é elevada quando seus inimigos naturais não estão presentes na área de cultivo.

\section{Agradecimentos}

Ao CNPq, pelo financiamento deste trabalho.

\section{Referências}

BRASIL. Ministério da Agricultura, Pecuária e Abastecimento. Agronegócio brasileiro: desempenho do comércio exterior. Brasília: SPC, 2004. 104p.

CRUZ, I. A lagarta-do-cartucho na cultura do milho. Sete Lagoas: Embrapa-CNPMS, 1995. 45p. (Embrapa-CNPMS. Circular técnica, 21).

CRUZ, I. Controle biológico em manejo integrado de pragas. In: PARRA, J.R.P.; BOTELHO, P.S.M.; CORREA-FERREIRA, B.S.; BENTO, J.M.S. (Ed.). Controle biológico no Brasil: parasitóides e predadores. São Paulo: Manole, 2002. p.543-570.

CRUZ, I.; FIGUEIREDO, M.L.C.; OLIVEIRA, A.C.; VASCONCELOS, C.A. Damage of Spodoptera frugiperda (Smith) in different maize genotypes cultivated in soil under three levels of aluminium saturation. International Journal of Pest Management, v.45, p.293-296, 1999.

CRUZ, I.; GONÇALVES, E.P.; FIGUEIREDO, M.L.C. Effect of a nuclear polyhedrosis virus on Spodoptera frugiperda (Smith) larvae, its damage and yield of maize crop. Revista Brasileira de Milho e Sorgo, v.1, p.20-27, 2002.
CRUZ, I.; TURPIN, F.T. Yield impact of larval infestation of the fall armyworm Spodoptera frugiperda (J.E. Smith) to mid-whorl growth stage of corn. Journal of Economic Entomology, v.76, p.10521054, 1983.

FIGUEIREDO, M.L.C. Interação de inseticidas e controle biológico natural na redução dos danos de Spodoptera frugiperda (J.E. Smith, 1797) (Lepidoptera: Noctuidae) na cultura do milho. 2004. 205p. Tese (Doutorado) - Universidade Federal de São Carlos, São Carlos.

FIGUEIREDO, M.L.C.; CRUZ, I.; DELLA LUCIA, T.M.C. Controle integrado de Spodoptera frugiperda (Smith \& Abbott) utilizando-se o parasitóide Telenomus remus Nixon. Pesquisa Agropecuária Brasileira, v.34, p.1975-1982, 1999.

GOMES, M. de S.; VON PINHO, R.G.; OLIVEIRA, J.S.; RAMALHO, M.A.P.; VIANA, A.C. Adaptabilidade e estabilidade de cultivares de milho para produtividade de matéria seca e degradabilidade ruminal da silagem. Revista Brasileira de Milho e Sorgo, v.1, p.83-90, 2002.

IRWIN, M.E.; GILL, R.W.; GONZALES, D. Field-cage studies of native egg predators of the pink Bollworm in southern California cotton. Journal of Economic Entomology, v.67, p.193-196, 1974.

LENTEREN, J.C. van. Critérios de seleção de inimigos naturais a serem utilizados em programas de controle biológico. In: BUENO, V.H.P. (Ed.). Controle biológico de pragas: produção massal e controle de qualidade. Lavras: Ufla, 2000. p.1-19.

LINGREN, P.D.; RIDGWAY, R.L.; JONES, S.L. Consumption by several common arthropod predators of eggs and larvae of two Heliothis species that attack cotton. Annals of the Entomological Society of America, v.61, p.613-618, 1968.

MARENCO, R.J.; FOSTER, R.E.; SANCHEZ, C.A. Sweet corn response to fall armyworm (Lepidoptera: Noctuidae) damage during vegetative growth. Journal of Economic Entomology, v.85, p.12851292, 1992.

MELO, W.M.C.; VON PINHO, R.G.; CARVALHO, M.L.M.; VON PINHO, E.V.R. Avaliação de cultivares de milho para produção de silagem na região de Lavras - MG. Ciência e Agrotecnologia, v.23, p.31-39, 1999.

MONTEIRO, M.A.R. Desempenho de cultivares de milho para produção de grãos e forragem no Estado de Minas Gerais. 1998. 53p. Dissertação (Mestrado) - Universidade Federal de Lavras, Lavras.

PREZOTO, F.; MACHADO, V.L.L. Ação de Polistes (Aphanilopterus) simillimus Zikán (Hymenoptera: Vespidae) na produtividade de lavoura de milho infestada com Spodoptera frugiperda (Smith) (Lepidoptera: Noctuidae). Revista Brasileira de Zoociências, v.1, p.19-30, 1999.

VAN DEN BOSCH, R.; LEIGH, T.F.; GONZALEZ, D.; STINNER, R.E. Cage studies on predators of the bollworm in cotton. Journal of Economic Entomology, v.62, p.1486-1489, 1969.

WISEMAN, B.R.; PAINTER, R.H.; WASSOM, C.E. Detecting corn seedling diferrences in the greenhouse by visual classification of damage by the fall armyworm. Journal of Economic Entomology, v.59, p.1211-1214, 1966. 